\title{
Sobre la interpretación del arte
}

Por Liliana Dosamantes Monteverde

Alumna del $V$ semestre de la

Licenciatura en Música

En un inicio, este trabajo pretendía responder a la pregunta ¿En qué fundar la estética? Sin embargo, durante su desarrollo se orientó hacia la interpretación y percepción del arte. Este giro se dio a partir de que sin darle muchas vueltas, fundé la estética, así como si fuera el primer bloque de un edificio, sobre el pensamiento de Kant, ya que él introdujo el juicio del gusto en el siglo XVIII (Abad, 1990). Junto con esto se presenta una cuestión fundamental en la interpretación y percepción del arte. Esta es que la gente no es la misma que hace cien, doscientos o mil años atrás, a pesar de que podemos aplicar el conocimiento de antiguos pensadores nunca seremos capaces de ver el mundo exactamente de la misma manera. Este cambio se encapsula muy bien dentro del concepto de "sujeto contemporáneo" (Agamben, 2011), ese que se identifica, tiene pensamiento crítico, se actualiza, interpreta y responde al mundo según lo que él le da y en la actualización de la noción de "sensibilidad contemporánea" de Sánchez Vázquez (1992), según la cual nosotros nos relacionamos con los objetos desde nuestra época, desde nuestra sensibilidad contemporánea.

Es difícil buscar un fundamento sólido para un fenómeno que constantemente cambia y además, se complementa con todo lo que toca. Si bien pudiéramos tener una percepción más normativa sobre la estética, para que pudiera aplicarse realmente a la actualidad no creo que podamos verlo tan rígidamente como vemos un edificio. Heráclito decía que un hombre no puede bañarse dos veces en el agua del mismo río, en este caso creo que pudiéramos ver la estética, más bien, como una balsa o un barco ya que a pesar de que su estructura es sólida y resistente, el mar por el que pasa no es el mismo aunque sea el mismo.

Creo que el arte tiene cierto carácter caótico, dado por el gran espacio enmarañado que hay entre el logro humano ${ }^{1}$ artístico y su recepción. Asimismo, el arte tiene una capacidad única para capturar la realidad (que es indeterminada, indiferenciada y parcial) sin reducirla, a diferencia de lo que ocurre en las ciencias (Rojas, 2003). Rojas dice que el arte, al igual que el resto de nuestras actividades va en función de comprender el caos en el que vivimos, ya que la realidad aparentemente es algo y no un todo.
Además de la característica de representación de totalidades, el arte es un medio por el cual se acelera el proceso de institución de convenciones, decía Hauser, ya que va en contra del naturalismo o de sometimiento mimético a la realidad. Francastel también aborda esta cuestión diciendo que el arte no solo contiene ideas predominantes o nos brinda información sobre el mundo sino que es un medio por el cual se experimenta y aprehende el mundo (como se cita en Rojas, 2003). Por ejemplo, podemos ver esta institución de convenciones con el famoso símbolo de corazón. Este ha existido por unos mil años y ¿Qué tiene que ver con la forma real de un corazón? ¿Por qué se relaciona con el amor? Si yo hubiera tratado de representar el amor o en general los sentimientos con algún órgano del cuerpo hubiera escogido el estómago, que considero tiene un poco más de sentido, pero no fue así, fue el corazón que no tiene forma de corazón real lo que se instituyó. Fueron dos pequeños procesos relacionados a esta convención: el primero de relacionar el signo de la figura de corazón con el órgano corazón y el segundo de actualizarlo y darle la connotación sentimental. Ahora es muy difícil ver un corazón y no relacionarlo inmediatamente con lo romántico.

En este sentido, es Castoriadis (2005), quien aborda el proceso de institucionalización de la sociedad. El hombre crea instituciones, las instituye y las demarca temporalmente, el lenguaje es, p. Ej., una institución imaginaria creada por nosotros o el sentido del corazón, las instituye como creaciones sociales; pero en ese esfuerzo permanente de creación imaginaria, crea también lo instituyente, nuevas instituciones que entran en conflicto con las anteriores y, esto, lo podemos poner en relación con las nociones de sujetos contemporáneos y sensibilidad contemporánea. Vivimos una época de profundas transformaciones que demandan de nosotros formas de interpretación adecuadas a la época. Las instituciones se van transformando junto con la sociedad; las interpretaciones del arte, sin embargo, representan un problema ya que para poder hablar de cómo afecta a sus receptores todos deberíamos ser capaces de interpretar y/o producir arte; aunque creo que de cualquier manera, nuestras diferentes posturas o incluso la ignorancia de ciertos conocimientos nos estorbarían si quisiéramos llegar a una 
conclusión. Aquí es donde la historia y la sociología del arte nos ayudan a contextualizar una obra y delimitar las posibles interpretaciones para que no esté sujeta a la deriva de cualquier interpretación posible, pero tampoco se desea llegar a una única interpretación. Es posible encontrar ese punto intermedio, como dice Beuchot (2000).

La transformación de convenciones y este problema interpretativo se puede ejemplificar con una experiencia que tuve con el cuento La casa de Asterión de Borges (2000). Conociendo ya el mito del minotauro, leer este cuento fue casi una bofetada, estaba impresionada y triste porque jamás había visto la vida de esa manera: un juego en el que uno hace como que hace. Quise compartir ese sentimiento con quien se pudiera y en mi primer intento me topé con la sorpresa de que la persona a quien se lo compartí apenas tenía una vaga idea de quién era Asterión, así que obviamente, fallé. En el segundo intento, primero me aseguré de que esta persona conociera lo suficiente el mito de Asterión como para entender el cuento. Fallé de nuevo ya que mi conejillo de indias simplemente no encontró nada especial ni se acercó a la interpretación que le di y aún no sé exactamente a qué adjudicárselo. Llegué a preguntarme si realmente solo yo veía ese cuento de esa manera pero estaba bastante segura de que al menos Borges quiso decir lo que yo pensé al leerlo. Mi duda se aclaró cuando en Doctor Who ${ }^{2}$ apareció un alien que se veía como un minotauro. Cambiaron cosas como el laberinto por una nave espacial averiada y la razón de su comportamiento pero la esencia del personaje y lo que yo quería mostrar era lo mismo. Nunca pensé identificarme con un alienígena con forma de minotauro.

En este caso yo estaba tratando de imponer mi interpretación, quizá hasta normativamente, cuando estos nuevos receptores tenían una interpretación post modernista, y realmente era lo más esperado. No creo que sea tan fácil para el hombre moderno relacionarse ni con el mito del minotauro ni con el cuento del minotauro ni con el alien-minotauro. Las obras de arte se escapan de la caducidad por la implicación que tienen en la historia, mas "lo que hace que seamos sensibles a ellas no tiene que ver con que encarnen valores eternos; sino que ellas nos revelan la validez de sistemas de comunicación que hasta ese momento no habíamos captado y que no podrían expresarse más claramente por otros medios" (Rojas, 2003, pág. 416). A pesar de que el mito original del minotauro vaya a desaparecer de la memoria colectiva muy pronto, la figura del minotauro nos seguirá acompañando gracias a las adaptaciones más llamativas para la audiencia actual como la que aparece en Doctor Who. De ahí la relevancia de las nociones de sujeto y sensibilidad contemporánea que señalé arriba.

El arte a final de cuentas es un lenguaje, la historia del arte es la historia de los medios de representación que van progresando conforme avanza la cultura y la tecnología. Si viéramos al arte como vemos a una persona, partiendo del renacimiento tenemos un arte figurativo, similar a lo que hace un bebé cuando comienza a hablar; en el siglo XIX podríamos ver al arte como un joven que entiende su entorno y actúa conforme a la experiencia; y del siglo XX en adelante como un adulto que tiene sus propias ideas, sigue sus propias normas, se entiende y se transforma a sí mismo. Solo queda esperar a que nunca llegue la muerte del arte, ahora sí, en el siglo XXI, con todas sus profundas transformaciones. Nosotros como artistas - y quizá no sólo los artistas- tenemos por trabajo la re-interpretación del símbolo como el signo por el que nos expresamos y adaptar nuestras obras al avance constante y desmesurado de nuestro contexto. Aunque existan siempre límites para la interpretación de todo, yo espero que nunca estemos de acuerdo porque a fin de cuentas, el contraponer nuestras diferencias es lo que hace que las disciplinas crezcan.

\footnotetext{
${ }^{1}$ Usamos el término logro humano artístico para diferenciarlo de producto o mercancía.

2 Serie británica de la compañía BBC que trata sobre un alienígena humanoide llamado "el Doctor" y sus aventuras viajando por el tiempo y espacio.
}

\section{Bibliografía}

Abad, F. (1990). La Estética de Kant en España. (Notas en el segundo centenario de la Crítica del juicio). Anuario de la Sociedad Española de Literatura General y Comparada, VIII, 25-29.

Agamben, G. (2011). Desnudez (M. Ruvituso, M. D’Meza \& C. Sardoy, Trans. 1a ed. Vol. 427). Buenos Aires: Adriana Hidalgo editora.

Beuchot, M. (2002). Perfiles esenciales de la hermeneútica. México: Unam.

Borges, J. L. (2000). El Aleph. Madrid: Alianza.

Castoriadis, C. (2005). Una sociedad a la deriva. Entrevistas y debates (1974-1997). Buenos Aires, Argentina: Katz.

Sánchez Vázquez, A. (1992). Invitación a la estética (1era ed ed.). Grijalbo: México. 